\section{Relationships between Insulin Secretion, Insulin Action, and Fasting Plasma Glucose Concentration in Nondiabetic and Noninsulin-dependent Diabetic Subjects}

\author{
C. Bogardus, S. Lillioja, B. V. Howard, \\ G. Reaven, and D. Mott \\ Phoenix Clinical Research Section, National Institute of Arthritis, \\ Diabetes, Digestive and Kidney Diseases, National Institutes \\ of Health, Phoenix, Arizona 85016
}

A

bstract. The relationships between insulin secretion, insulin action, and fasting plasma glucose concentration (FPG) were examined in 34 southwest American Indians (19 nondiabetics, 15 noninsulin-dependent diabetics) who had a broad range of FPG (88$310 \mathrm{mg} / 100 \mathrm{ml}$ ). Fasting, glucose-stimulated, and mealstimulated plasma insulin concentrations were negatively correlated with FPG in diabetics but not in nondiabetics. In contrast, fasting and glucose-stimulated plasma Cpeptide concentrations did not decrease with increasing FPG in either group and 24-h urinary C-peptide excretion during a diet of mixed composition was positively correlated with FPG for all subjects $(r=0.36, P<0.05)$. Fasting free fatty acid (FFA) was correlated with FPG in nondiabetics $(r=0.49, P<0.05)$ and diabetics $(r$ $=0.77, P<0.001)$. Fasting FFA was also correlated with the isotopically determined endogenous glucose production rate in the diabetics $(r=0.54, P<0.05)$. Endogenous glucose production was strongly correlated with FPG in the diabetics $(r=0.90, P<0.0001)$, but not in the nondiabetics. Indirect calorimetry showed that FPG was also negatively correlated with basal glucose oxidation rates $(r=-0.61, P<0.001)$, but positively with lipid oxidation $(r=0.74, P<0.001)$ in the diabetics. Insulin action was measured as total insulinmediated glucose disposal, glucose oxidation, and storage rates, using the euglycemic clamp with simultaneous indirect calorimetry at plasma insulin concentrations of $135 \pm 5$ and $1738 \pm 59 \mu \mathrm{U} / \mathrm{ml}$. These parameters of insulin

\footnotetext{
Address reprint requests to Dr. Bogardus. 1984.

Received for publication 10 April 1984 and in revised form 21 June
}

The Journal of Clinical Investigation, Inc.

Volume 74, October 1984, 1238-1246 action were significantly, negatively correlated with FPG in the nondiabetics at both insulin concentrations, but not in the diabetics although all the diabetics had markedly decreased insulin action. We conclude that decreased insulin action is present in the noninsulindependent diabetics in this population and marked hyperglycemia occurs with the addition of decreased peripheral insulin availability. Decreased peripheral insulin availability leads to increased FFA concentrations and lipid oxidation rates (and probably also increased concentrations of gluconeogenic precursors) that together stimulate gluconeogenesis, hepatic glucose production, and progressive hyperglycemia.

\section{Introduction}

Hyperglycemia may be due to decreased insulin action and/or decreased insulin secretion, and there is evidence $(1,2)$ that both defects occur in patients with noninsulin-dependent diabetes mellitus (NIDDM) ${ }^{1}$. There is also data suggesting that reduced insulin action may develop as a result of decreased insulin secretion (3-5). Thus, the relative contribution of either abnormality to the pathogenesis of hyperglycemia in NIDDM has been unclear. The hypothesis that decreased insulinmediated glucose disposal is primarily responsible for the development of NIDDM is based on several observations. Decreased insulin-mediated glucose disposal characterizes patients with either impaired glucose tolerance or NIDDM (2), and Kolterman et al. (6) have reported a significant, negative, linear correlation between magnitude of glycemia and maximal insulin-mediated glucose disposal in subjects with varying degrees of glucose intolerance. A similar correlation between measures of insulin secretion and glycemia has not been

1. Abbreviations used in this paper: EGPR, endogenous glucose production rate; FPG, fasting plasma glucose concentrations; $M$, total glucose disposal rate; NIDDM, noninsulin-dependent diabetes mellitus. 
observed (7-9). In addition, some patients with NIDDM and mild hyperglycemia have enhanced insulin responses after oral glucose (7-9), and those with marked hyperglycemia have meal-stimulated insulin responses equivalent to subjects with normal glucose tolerance (10).

Insulin secretory data are also the basis of an alternative hypothesis that proposes abnormal pancreatic beta cell function as the fundamental defect leading to the development of NIDDM. In this hypothesis, reduced (glucose-stimulated) or equivalent (meal-stimulated) insulin responses observed in markedly hyperglycemic subjects with NIDDM are viewed as insufficient insulin secretion for the degree of glycemia. Additional evidence of abnormal beta cell function, as recently reviewed by DeFronzo and Ferrannini (11), are the absent and/or delayed early insulin responses observed in subjects with NIDDM and the low insulin response of normoglycemic "prediabetics."

Evaluation of the two hypotheses is potentially misleading, however, since no study is available in which both insulin secretion and insulin action were measured on one group of individuals. Therefore, we initiated the present investigation in which we have quantified insulin secretion and insulin action in a group of southwest American Indians with a wide range of fasting glycemia. Insulin secretion was assessed by measuring insulin and C-peptide responses after oral glucose and during a diet of mixed composition. In vivo insulin action was estimated by using the euglycemic clamp technique, with simultaneous indirect calorimetry, at both submaximal and maximally stimulating insulin concentrations.

\section{Methods}

34 southwest American Indians were admitted to the clinical research ward for study (Table I). After written informed consent was obtained, all subjects were physically examined and a 12-lead electrocardiogram recorded. After an overnight fast, blood was drawn for complete blood count, liver function tests, blood urea nitrogen, creatinine, electrolytes, calcium, total protein, and albumin. No subjects were taking medications and all had a normal physical examination, electrocardiogram, and blood tests. The percent body fat of each volunteer was estimated by underwater weighing with correction for the simultaneously measured residual lung volume (12). After $3 \mathrm{~d}$ of a weight-maintaining diet containing at least $200 \mathrm{~g}$ carbohydrate/d, and after a 10-h overnight fast, an oral glucose tolerance test was performed (13). Blood for plasma glucose, insulin, and C-peptide determination were drawn through an indwelling intravenous catheter at $-15,0,30,60,120$, and $180 \mathrm{~min}$. Blood for determination of fasting plasma free fatty acid (FFA) concentration was drawn into iced tubes containing EDTA paraoxon (Sigma Chemical Co., St. Louis, MO) at $-15,-7$, and 0 min.

Each subject's glucose tolerance was classified according to the National Diabetes Group Criteria (13). There were 19 nondiabetics $(8$ females, 11 males) and 15 noninsulin-dependent diabetics (11 females, 4 males). The nondiabetic group in this study included subjects who had normal glucose tolerance, impaired glucose tolerance, or were classified as "nondiagnostic." The diabetics were slightly older and shorter than the nondiabetics but were equally obese.

Response to diet of mixed composition. After the oral glucose tolerance test, and after a 10-h overnight fast, an indwelling intravenous catheter was placed in an arm vein at $0700 \mathrm{~h}$. Breakfast was offered at $0730 \mathrm{~h}$, lunch at $1130 \mathrm{~h}$, dinner at $1630 \mathrm{~h}$, and a snack at $1930 \mathrm{~h}$. The meals were eaten over a 20 -min period. The breakfast meal contained $30 \%$, lunch $30 \%$, dinner $30 \%$, and the snack $10 \%$ of the weight-maintaining caloric requirements. The diet was comprised of $20 \%$ protein, $40 \%$ carbohydrate, and $40 \%$ fat. Blood for plasma insulin was drawn through the indwelling catheter $15 \mathrm{~min}$ before and just prior to starting the breakfast meal, and thereafter every $30 \mathrm{~min}$ for 9 $\mathrm{h}$, or for $5 \mathrm{~h}$ following the lunch meal. Blood for plasma FFA determination was drawn at -15 and $-7 \mathrm{~min}$, and just prior to starting the breakfast meal. On the same day beginning at $0700 \mathrm{~h}$, a 24-h urine collection was begun for determination of C-peptide excretion.

Euglycemic clamp. After the meal test and after a 10-h overnight fast, an intravenous cathether was placed in an antecubital vein for infusion of insulin, glucose, and [3- $\left.\mathrm{H}^{3}\right]$ glucose. A primed continuous infusion of $\left[3-\mathrm{H}^{3}\right]$ glucose was then begun and continued until the end of the study. In normoglycemic subjects, the $\left[3-\mathrm{H}^{3}\right]$ glucose was given as a $30 \mu \mathrm{Ci}$ bolus followed by a continuous infusion of $0.30 \mu \mathrm{Ci} / \mathrm{min}$. In subjects with fasting hyperglycemia, the bolus and continuous infusion were increased by a factor equal to the fasting glucose

Table I. Subject Characteristics

\begin{tabular}{|c|c|c|c|c|c|}
\hline & Age & Height & Weight & $\begin{array}{l}\text { Body } \\
\text { fat* }\end{array}$ & $\begin{array}{l}\text { Fasting } \\
\text { glucose }\end{array}$ \\
\hline & $y r$ & $c m$ & $\mathrm{~kg}$ & $\%$ & $\mathrm{mg} / 100 \mathrm{ml}$ \\
\hline \multicolumn{6}{|l|}{ Nondiabetics } \\
\hline Mean \pm SEM & $25 \pm 2$ & $170 \pm 1.9$ & $104.3 \pm 6.4$ & $35 \pm 2$ & $99 \pm 2$ \\
\hline Range $(n=19)$ & $18-45$ & $154.0-183.0$ & $59.8-169.8$ & $21-49$ & $88-116$ \\
\hline \multicolumn{6}{|l|}{ Diabeticsł } \\
\hline Mean \pm SEM & $32 \pm 3 \S$ & $163.5 \pm 2.5 \S$ & $98.6 \pm 7.2$ & $38 \pm 2$ & $219 \pm 14 \S$ \\
\hline Range $(n=15)$ & $19-53$ & $151.0-184.5$ & $59.8-175.3$ & $33-45$ & $118-310$ \\
\hline
\end{tabular}

* Percent body fat was determined by underwater weighing. $¥$ Diabetic status was assigned according to the National Diabetes Group Criteria. $\S$ Significant difference between nondiabetics and diabetics, $P<0.05$. 
concentration divided by 100 . Another catheter was placed retrograde in a dorsal vein of the contralateral hand for blood withdrawal. The hand was kept in a warming box at $70^{\circ} \mathrm{C}$. After $2.5 \mathrm{~h}$, four blood samples were drawn over a 30-min period for determination of [3$\mathrm{H}^{3}$ gglucose specific activity. A primed-continuous $\left(40 \mathrm{mU} / \mathrm{m}^{2} \cdot \min \right)$ insulin infusion (Nordisk; Bethesda, MD) was then started and continued for $340 \mathrm{~min}$. This resulted in a mean plasma insulin concentration of $135 \pm 5 \mu \mathrm{U} / \mathrm{ml}$ when measured on five blood samples drawn between 300 and $340 \mathrm{~min}$. Another primed-continuous insulin infusion (400 $\mathrm{mU} / \mathrm{m}^{2} \cdot \mathrm{min}$ ) was then started and continued for $80 \mathrm{~min}$. This resulted in a mean plasma insulin concentration of $1738 \pm 59 \mu \mathrm{U} / \mathrm{ml}$ when measured between 40-80 min later. After the start of the initial insulin infusion, a variable infusion of $20 \%$ glucose was given as necessary to maintain the plasma glucose concentration at $100 \mathrm{mg} / 100 \mathrm{ml}$ for all subjects. Thus, in the hyperglycemic subjects, the glucose infusion was not begun until the plasma glucose concentration had declined to 100 $\mathrm{mg} / 100 \mathrm{ml}$. In this way, all subjects were studied at the same plasma glucose concentration and were exposed to insulin for the same time. Blood for plasma glucose concentration was drawn every $5 \mathrm{~min}$ throughout the test. The mean plasma glucose concentration was $102 \pm 0.4 \mathrm{mg} / 100 \mathrm{ml}$ (mean coefficient of variance $=2.2 \%$ ), and $101 \pm 0.4$ $\mathrm{mg} / 100 \mathrm{ml}$ (mean coefficient of variance $=3.0 \%$ ) during the last 40 min of the low (300-340 min) and high dose insulin infusion (380$420 \mathrm{~min}$ ), respectively. In addition to drawing blood for fasting insulin and $\mathrm{C}$-peptide determination, blood for plasma insulin and $\left[3-\mathrm{H}^{3}\right.$ ]glucose specific activity was drawn every $10 \mathrm{~min}$ from $300-340$ and from 380 $420 \mathrm{~min}$.

Indirect calorimetry. $1 \mathrm{~h}$ before the start of the insulin infusions, a clear, plastic, ventilated hood was placed over the subject's head. Room air was drawn through the hood and the flow rate measured by a pneumotachograph (Gould, Inc., Cleveland, $\mathrm{OH}$ ). A constant fraction of expired air was withdrawn and analyzed for oxygen and carbon dioxide content. The oxygen analyzer was a zirconium cell analyzer and the carbon dioxide analyzer was an infrared analyzer (Applied Electrochemistry, Sunnyvale, CA). The analyzers and flowmeter were connected to a desktop computer (Hewlett-Packard, Palo Alto, CA). This recorded continuous, integrated calorimetric measurements every 5 min for the hour before and from 280 to $\mathbf{4 2 0}$ min after the start of the insulin infusion. The protein oxidation during the test was estimated from the urinry urea production rate. The nonprotein respiratory quotient was then calculated and the substrate oxidation rates determined from the equations of Lusk (14).

Calculations and analyses. The appearance rate $(\mathrm{Ra})$ of glucose in the plasma was calculated from the blood $\left[3-\mathrm{H}^{3}\right]$ glucose specific activities using Steele's equations (15). In the resting, absorptive state, the $\mathrm{Ra}$, which was calculated from Steele's steady state equations, is equal to the endogenous glucose production rate (EGPR) since there is no exogenous glucose infusion. During the euglycemic clamp, the EGPR equals the difference between the exogenous glucose infusion rate and the $\mathrm{Ra}$ calculated using Steele's nonsteady state equations (EGPR $=\mathbf{R a}$ - exogenous glucose infusion rate). When the Ra equals the exogenous glucose infusion rate, the EGPR is assumed to be completely suppressed so that the total glucose disposal rate equals the exogenous glucose infusion rate. These data were calculated for each 20-min period between $300-340$ and 380-400 min during the euglycemic clamp, and then, averaged to calculate the total glucose disposal, or $M$ value, at the low and high insulin concentration, respectively. The basal and insulin-stimulated carbohydrate oxidation rates were calculated from the indirect calorimetric data by averaging the data for $\mathbf{4 0 ~ m i n ~ p r i o r ~ t o ~ t h e ~ b e g i n n i n g ~ o f ~ t h e ~ i n s u l i n ~ i n f u s i o n ~ a n d ~ f o r ~ t h e ~}$ last $40 \mathrm{~min}$ during the low and high dose insulin infusion. The carbohydrate storage rate during both insulin infusions was estimated by subtracting the carbohydrate oxidation rate from the $M$.

Plasma insulin concentrations were determined using the Herbert modification (16) of the radioimmunoassay of Yalow and Berson (17). Plasma and urinary C-peptide concentrations were determined by radioimmunoassay as previously described (18). Bacterially synthesized human C-peptide was used as standard (19) and was also used to prepare ${ }^{125} \mathrm{I}$-C-peptide (20) and goat anti-human-C-peptide antiserum. Materials for the C-peptide assay were generously provided by Lilly Laboratories (Indianapolis, IN). Tritiated glucose specific activity in blood samples was determined after precipitating protein with perchloric acid as described by others (21). Plasma FFA concentration was determined using the Saloni and Sardina cupric salt method modified as described previously (22).

For comparisons between the results of the hyperinsulinemic, euglycemic clamp, and the fasting plasma glucose concentration (FPG), the FPG is the mean of four determinations performed on blood drawn the same morning. The plasma FFA concentration, available on 30 of the 34 subjects, is reported as the mean of determinations on three fasting samples from the day of the oral glucose tolerance test and three fasting samples drawn on the morning of the mixed diet. For comparisons between the plasma FFA concentration and FPG, the FPG is the mean of four blood samples drawn on the same days as the blood for FFA determination. The insulin response $(n=32)$ and the C-peptide response $(n=29)$ to oral glucose and the insulin response $(n=32)$ to the mixed diet were calculated as the area under the curves describing insulin and C-peptide concentrations vs. time.

Statistics. All data are expressed as the mean \pm SEM. All statistical analyses were calculated using Statistical Analysis System, SAS Institute, Inc., Cary, NC.

\section{Results}

Fasting values. Fasting plasma insulin concentrations tended to increase up to a FPG of $\simeq 125 \mathrm{mg} / 100 \mathrm{ml}$, and declined with further increases in glycemia (Fig. 1). There was a positive relationship $(r=0.24)$ between FPG and insulin concentrations, which was not significant in the nondiabetics, in contrast to a significant negative correlation in the diabetics $(r=-0.69, P$ $<0.01)$. The mean $( \pm S E M)$ fasting plasma insulin concentration of the diabetics $(52 \pm 7 \mu \mathrm{U} / \mathrm{ml})$ was similar to that of the nondiabetics $(47 \pm 6 \mu \mathrm{U} / \mathrm{ml})$.

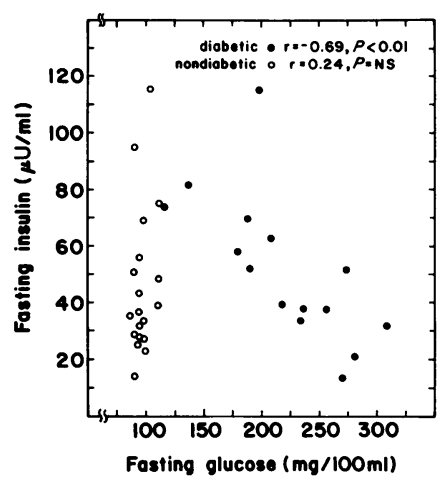

Figure 1. Relationship between fasting plasma insulin concentration and FPG. 


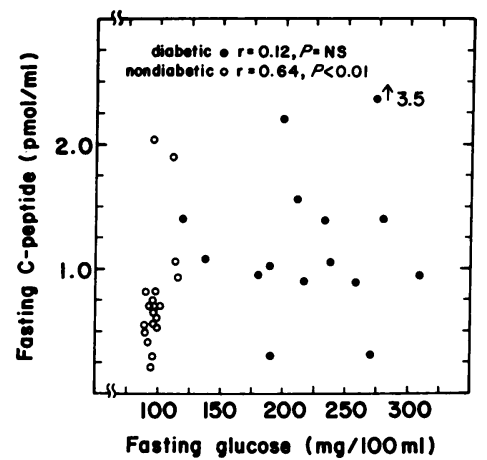

Figure 2. Relationship between fasting plasma $\mathrm{C}$ peptide concentration and FPG.

The relationship between fasting glycemia and plasma Cpeptide concentrations (Fig. 2) was generally similar to the relationship between fasting insulin and glucose concentrations. However, there were two differences in the diabetics. There was no negative correlation between fasting glycemia and fasting plasma C-peptide concentration in the diabetics. Furthermore, if plasma C-peptide concentrations were considered as an estimate of insulin secretion, diabetics secreted more insulin than nondiabetics, $1.3 \pm 0.2$ vs. $0.8 \pm 0.1 \mathrm{pmol} / \mathrm{ml}$ $(P<0.05)$, respectively.

There was a simple, linear relationship between fasting glucose and FFA concentration in the entire population $(r=0.83, P<0.001)$, and this was also found when nondiabetics $(r=0.49, P<0.05)$ and diabetics $(r=0.77, P<0.001)$ were considered separately (Fig. 3 ). FFA was also positively correlated with the isotopically determined EGPR in the diabetics ( $r=0.54, P=0.05$ ) but not in the nondiabetics.

FPG was strongly and linearly correlated with EGPR $(r$ $=0.93, P<0.001$ ) for all subjects (Fig. 4). The correlation between these variables in the nondiabetic subjects $(r=0.33)$ was not statistically significant when analyzed separately, but a strong correlation was observed in the diabetics $(r=0.90, P$ $<0.001)$. The simultaneously measured indirect calorimetry

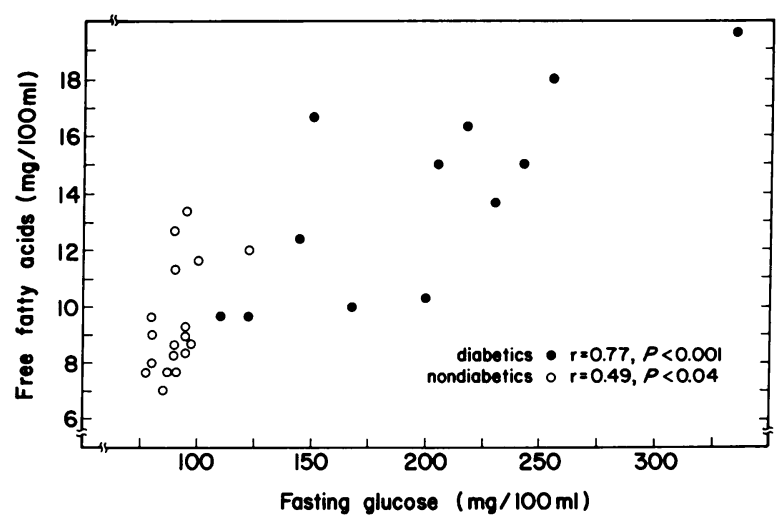

Figure 3. Relationship between fasting plasma FFA concentration and FPG.
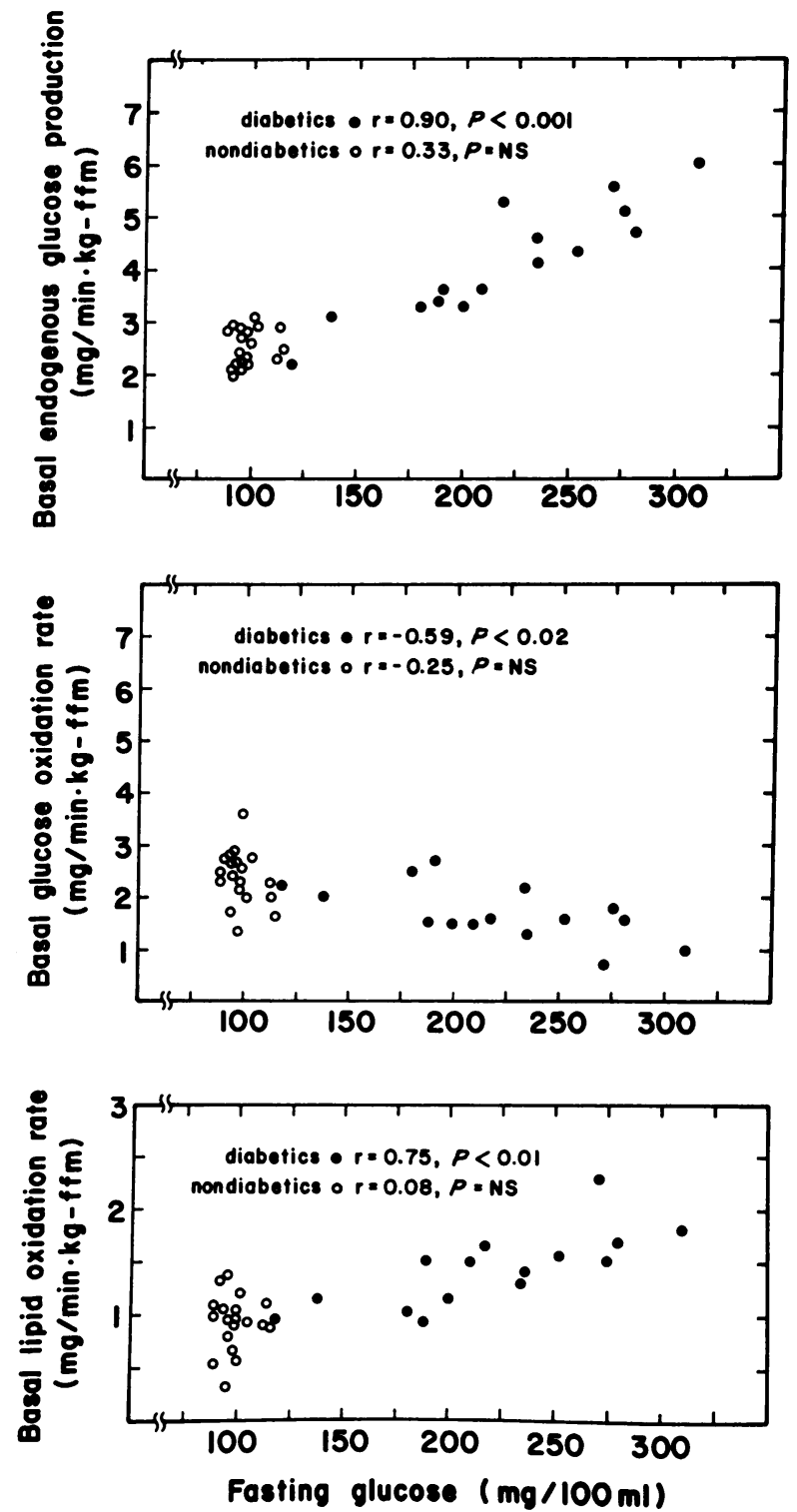

Figure 4. Relationships between the (A) EGPR, $(B)$ basal glucose oxidation rate, $(C)$ basal lipid oxidation rate and FPG.

data showed that there was a negative correlation between basal glucose oxidation rate and FPG $(r=-0.61, P<0.001)$ for all subjects, with a significant correlation observed in diabetics $(r=-0.59, P<0.02)$ but not in nondiabetics $(r=-0.25)$. In contrast, lipid oxidation rate correlated positively with fasting glucose in all subjects $(r=0.74, P<0.0001)$. This correlation was not significant for nondiabetics $(0.08)$, but was significant in the diabetics $(r=0.75, P<0.01)$.

Stimulated plasma glucose and $C$-peptide levels. The relationship between FPG and insulin responses to $75 \mathrm{~g}$ of oral glucose and to mixed meals are depicted in Figs. 5 and 6, 


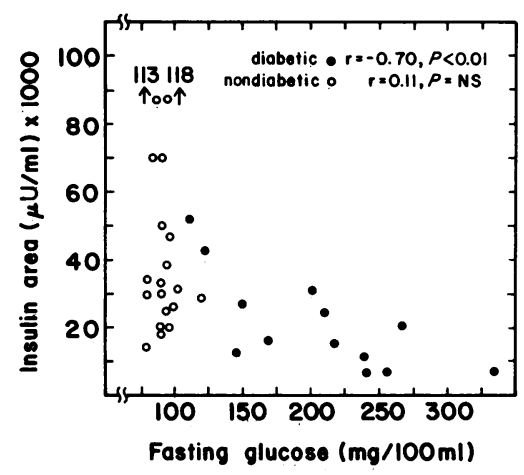

Figure 5. Relationship between the FPG and the plasma insulin response after oral glucose.

respectively, and resemble the relationship between fasting plasma insulin concentration and FPG. Thus, insulin responses to both stimuli increased in general up to fasting glucose concentrations of $\simeq 125 \mathrm{mg} / 100 \mathrm{ml}$, and then declined as magnitude of hyperglycemia increased further. As a result, there was a significant negative correlation between magnitude of glycemia and insulin response in diabetics to both oral glucose $(r=-0.70, P<0.01)$ and to meals $(r=-0.65, P$ $<0.01)$. The mean insulin response of the diabetics $(22 \pm 4$ $\mathrm{mU} / \mathrm{ml} \cdot 180 \mathrm{~min}$ ) was approximately half that of the nondiabetics $(44 \pm 7 \mathrm{mU} / \mathrm{ml} \cdot 180 \mathrm{~min})(P<0.01)$ following oral glucose, whereas the mean insulin responses of the two groups to the test meals were similar $(77 \pm 4$ and $87 \pm 11 \mathrm{mU} / \mathrm{ml} \cdot 180$ min, respectively).

There was no significant correlation between C-peptide response and fasting glycemia in the entire population, or in either subgroup (Fig. 7). Specifically, there was not a negative correlation between C-peptide response to glucose and severity of diabetes. Furthermore, total C-peptide responses to oral glucose was similar for both subgroups, $304 \pm 46$ vs. $351 \pm 47$

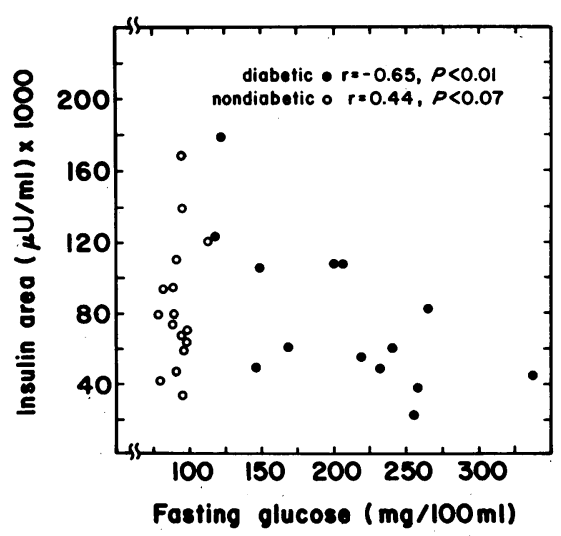

Figure 6. Relationship between FPG and insulin response for $9 \mathrm{~h}$ during the mixed diet.

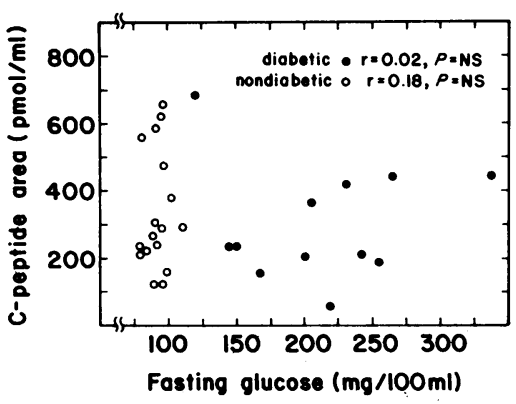

Figure 7. Relationship between FPG and the plasma C-peptide response after oral glucose.

$\mathrm{mol} / \mathrm{ml} \cdot 180 \mathrm{~min}$ in diabetics and nondiabetics, respectively. Daily urinary C-peptide excretion was positively correlated (Fig. 8) $(r=0.36, P<0.05)$ with fasting glycemia in all subjects, and patients with NIDDM excreted significantly more ( $P$ $<0.05)$ C-peptide $(66 \pm 8 \mathrm{nmol} / \mathrm{d})$ than did the nondiabetics $(45 \pm 7 \mathrm{nmol} / \mathrm{d})$.

Hyperinsulinemic, euglycemic clamp studies. Although there was a significant, negative relationship within the whole population between FPG and M during the low dose $(r=-0.67)$ and high dose $(r=-0.68)$ clamps, inspection of Figs. 9 and 10 indicated that this was a misleading generalization. $M$ declined over a narrow range of plasma glucose concentration in nondiabetics, resulting in a significant negative relationship between $\mathrm{M}$ and fasting glucose during both clamp studies ( $r$ $=-0.64$ and $-0.60, P<0.01)$. In contrast, there was essentially no further fall in $M$ in diabetics over almost a threefold increase in degree of hyperglycemia. As a result, there was not a significant relationship between degree of fasting hyperglycemia and glucose disposal in diabetics.

The relationship between fasting glycemia and glucose storage and oxidation displayed the same pattern. FPG correlated inversely with glucose oxidation rate during the low dose and high dose insulin infusion in the nondiabetic group ( $r$

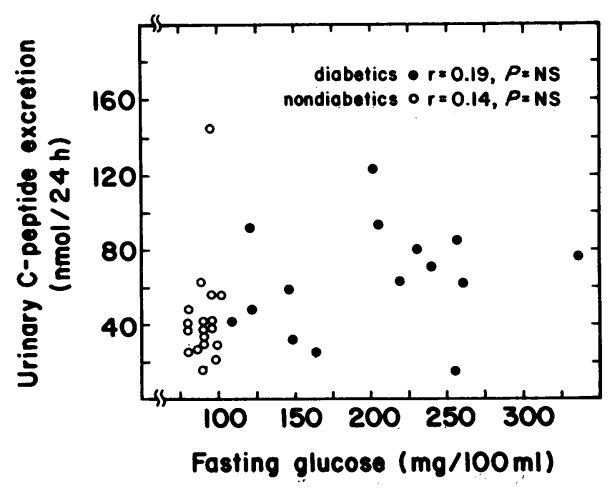

Figure 8. Relationship between FPG and 24-h urinary C-peptide excretion. 

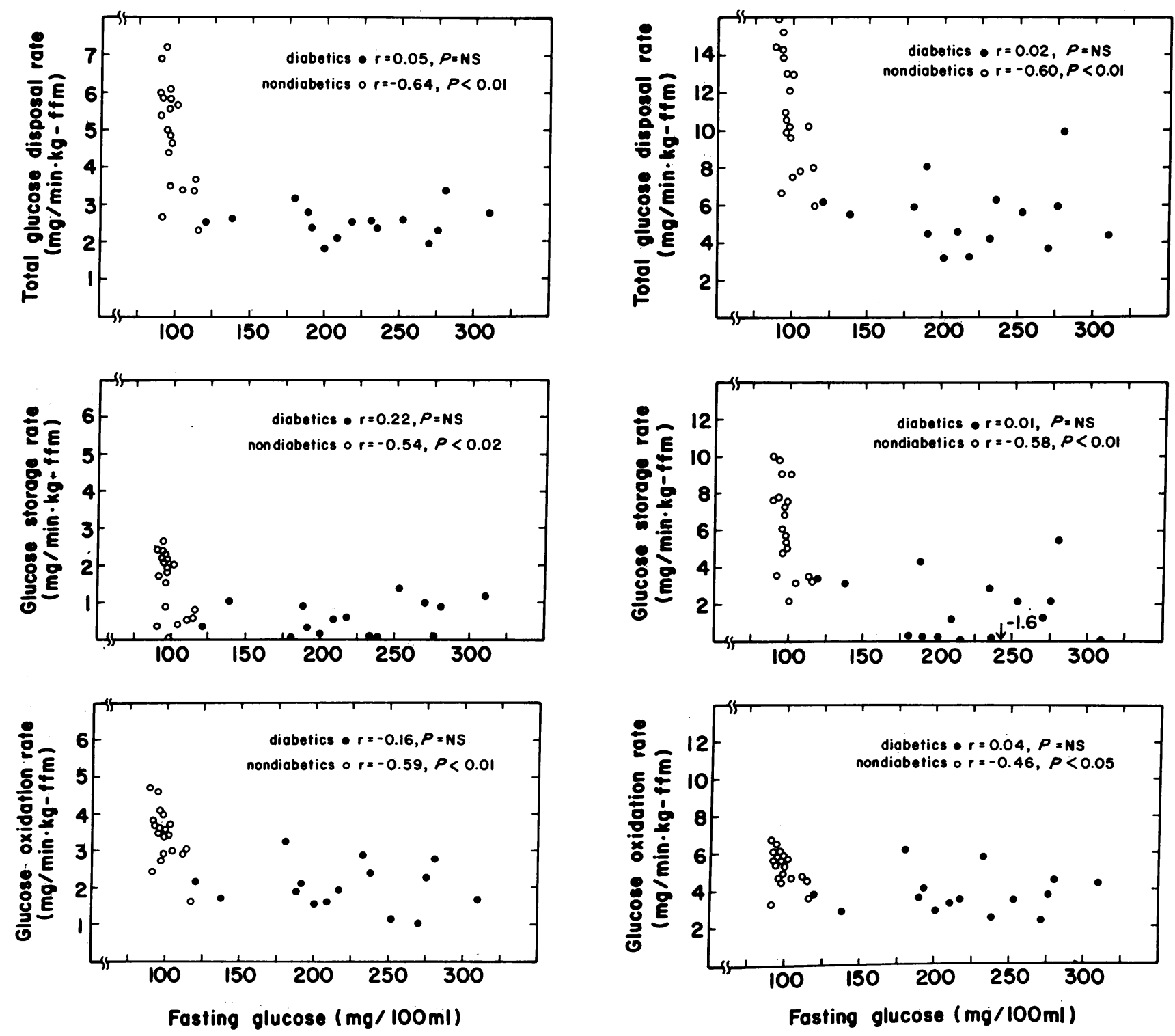

Figure 9. Relationship between $(A)$ total glucose disposal rate, $(B)$ glucose storage rate, and $(C)$ glucose oxidation rate during the euglycemic clamp and FPG. Mean \pm SEM plasma insulin concentration was $135 \pm 5 \mu \mathrm{U} / \mathrm{ml}$.

$=-0.59, P<0.01$ and $r=-0.46, P<0.05$, respectively), but not in the diabetic group. The glucose storage rate also inversely correlated with fasting glucose in the nondiabetics $(r$ $=-0.54, P<0.02$ and $r=-0.58, P<0.01$ ), but not in the diabetics. As can be seen in Figs. 9 and 10, decreased glucose storage and oxidation appeared to contribute approximately equally to the decreased net glucose disposal in the diabetic subjects during the low dose insulin infusion. During the high dose insulin infusions, decreased glucose disposal in the diabetics was mainly due to decreased glucose storage rates.

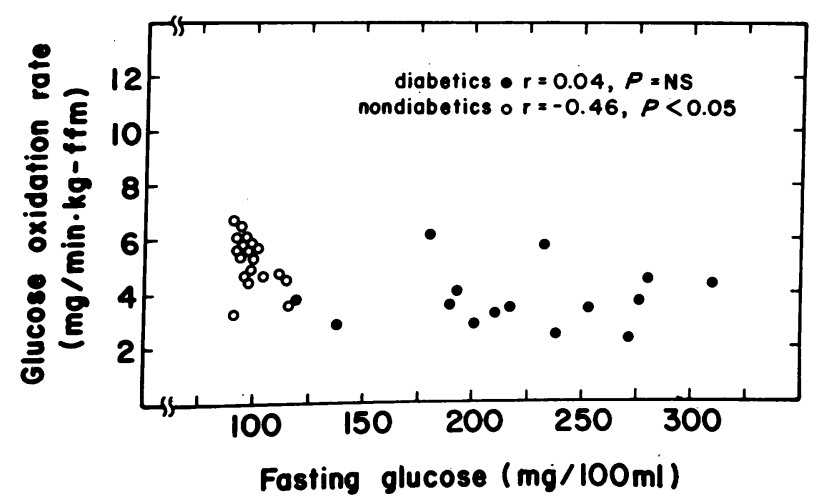

Figure 10. Relationship between $(A)$ total glucose disposal rate, $(B)$. glucose storage rate, and $(C)$ glucose oxidation rate during the euglycemic clamp and FPG. Mean \pm SEM plasma insulin concentration was $1738 \pm 59 \mu \mathrm{U} / \mathrm{ml}$.

During the low dose insulin infusion, EGPR was inhibited between 31 and $100 \%$. The suppressibility of the EGPR was unrelated to degree of fasting hyperglycemia. During the higher dose insulin infusions, EGPR was completely suppressed in 31 of 34 subjects.

\section{Discussion}

The current study was initiated to examine the relationship between insulin secretion, insulin action, and fasting glycemia 
in nondiabetic- and noninsulin-dependent diabetic subjects. If the major defect responsible for the development of hyperglycemia in both nondiabetic and diabetic subjects was decreased insulin action, it might be anticipated that a negative linear correlation would exist between the rate of insulin-mediated glucose disposal and the magnitude of glycemia over the entire range of glycemia. It was obvious on inspection of Figs. 9 and 10 that the relationship was more complicated. There was a marked fall in total insulin-stimulated $\mathbf{M}$, glucose oxidation, and storage over a small range of FPG in nondiabetic subjects (normal glucose tolerance, nondiagnostic, and impaired glucose tolerance), and these variables of insulin action were well correlated with FPG during both insulin infusions. In contrast, there was no significant fall in $\mathbf{M}$, glucose oxidation, or glucose storage over a wide range of FPG in patients with NIDDM at either insulin concentration.

However, all the diabetics had decreased insulin action, and during the high dose insulin infusion, this was primarily due to reduced insulin-mediated glucose storage rates. The cause of the defect remains unknown but we have previously reported a good correlation between muscle glycogen synthase activation and glucose storage rates during high and low dose insulin infusions in 25 of these 34 subjects (23). This suggests that the measured decrease in glucose storage rates may reflect reduced insulin-stimulated glycogen synthetic rates. Decreased insulin-mediated glucose oxidation rates also contributed to reduced insulin action, but was quantitatively more important during the low dose insulin infusions. Recent preliminary data from our laboratory (24) suggests that decreased glucose oxidation is a result of higher plasma FFA concentrations and associated increased lipid oxidation rates, as predicted by the "glucose-fatty acid cycle" hypothesis (25).

The alternative view to the primary importance of abnormal insulin action in the pathogenesis of NIDDM is that glycemia is related to decreased peripheral insulin availability over the entire range of glycemia. This hypothesis would predict a negative relationship between FPG and insulin concentrations over the entire range of fasting glycemia. Figs. 1, 2, and 5 suggest that this also was not the case. Fasting and postglucose load insulin concentrations displayed the "horseshoe" relationship first described by Reaven and Miller (7) and subsequently confirmed by many groups (11). Thus, the plasma insulin response to oral glucose tended to rise with small increases in FPG, followed by a progressive decline as the magnitude of hyperglycemia continued to increase. Secondly, although glucose-stimulated insulin concentrations in some patients with NIDDM were high or higher in absolute terms than those of normal glucose tolerant subjects, on the average, the postglucose insulin responses of diabetics were reduced. This was not true of either fasting or postmeal-stimulated insulin concentrations, which were similar in diabetics and nondiabetics.

Analysis of the C-peptide data suggested that glycemia may not be negatively related to pancreatic beta cell function. Both fasting plasma C-peptide concentration and 24-h urinary excretion of C-peptide were significantly increased in diabetics as compared with nondiabetics. There also was no negative relationship between C-peptide response to an oral glucose challenge and fasting hyperglycemia in diabetics, and the mean C-peptide response was equal to that of the nondiabetic group. Finally, 24-h urinary C-peptide excretion was increased in diabetics. Therefore, if C-peptide concentrations provide an estimate of insulin secretory function, the patients with NIDDM secreted as much or more insulin than the nondiabetics.

It was apparent that neither decreased insulin action or decreased peripheral insulin concentration by themselves could account for differences in glycemia in both diabetic and nondiabetic subjects. Contributions of both defects were necessary to explain the pathogenesis of hyperglycemia throughout the entire range of FPG. Small increases in fasting glycemia were associated with decreased insulin action, and hyperinsulinemia prevented more marked hyperglycemia in the nondiabetics. Thus, markedly reduced insulin action and increased secretion were characteristic of both nondiabetics with the highest glucoses within this group and of mildly hyperglycemic diabetics. If it is assumed, a priori, that any increase in fasting glycemia, even within this low range, should be prevented by even higher insulin concentrations, then the insulin secretory responses might be considered "relatively" insufficient. However, there is no data to support the assumption that "normally" functioning beta cells in the presence of mild hyperglycemia would secrete more than was observed in our subjects. Furthermore, recent evidence (26) suggests that mild hyperglycemia is necessary for "normal" subjects' pancreatic islets to compensate for insulin resistance and avoid more severe hyperglycemia. Whether decreased acute insulin responses also contributed to the development of mild hyperglycemia was not studied. However, analysis of previously published data from this population showed that subjects with FPG $<85 \mathrm{mg} / 100$ $\mathrm{ml}$, independent of the percent ideal weight, achieve similar peak acute insulin concentrations after intravenous glucose compared with subjects with plasma glucose concentrations from 95 to $117 \mathrm{mg} / 100 \mathrm{ml}(27)$.

Markedly hyperglycemic diabetics were characterized by both reduced insulin action and decreased peripheral insulin availability. The physiologic impact of relatively decreased peripheral insulin concentrations, in the presence of established "insulin resistance," were increased FFA concentrations, increased lipid oxidation rate, and decreased basal glucose oxidation rates. FFA and lipid oxidation were positively correlated with EGPR ( $r=0.54$ and $r=0.74)$ in the diabetics. In turn, FPG was strongly correlated with EGPR $(r=0.90)$. FFA and fat oxidation have been reported to stimulate gluconeogenesis and glucose production in other studies (28-30) in animals and man. Increased plasma concentrations of three carbon substrates are also known to stimulate gluconeogenesis and have previously been reported to be increased in subjects with NIDDM (31). The mechanisms for this increase is likely to be an inhibition of muscle pyruvate dehydrogenase by FFA (32). These three carbon compounds probably also have contributed to increased EGPR. We hypothesize therefore that, in these diabetic subjects, decreased insulin action and decreased peripheral insulin availability result in increased FFA concentra- 
tions, fat oxidation, and three carbon substrate concentrations. Together these stimulated hepatic gluconeogenesis, increased hepatic glucose production rate, and lead to progressive hyperglycemia.

An alternative hypothesis is that the liver is the central abnormal organ in the pathogenesis of marked hyperglycemia because of an intrinsic defect leading to decreasing sensitivity to insulin's and glucose's ability to decrease glucose production. If this defect was present, we would have predicted that the suppressibility of EGPR during the low dose insulin infusion would have been significantly, linearly correlated with fasting glycemia. This was not the case, and therefore, this seems a less satisfactory working hypothesis, at least with respect to insulin's action on the liver.

The inability to maintain the necessary degree of hyperinsulinemia may not be entirely due to beta cell failure. If estimates of insulin secretory function based upon plasma Cpeptide concentration and 24-h urinary C-peptide excretion are valid, our data suggested that diabetics actually secreted more insulin than did nondiabetics. Insulin secretory function in these subjects may be considered "insufficient," however, in the presence of the severe hyperglycemia. This could be a result of an inherited incapacity to increase insulin secretion to sufficient levels, rather than a result of a failing beta cell. In addition, the discordance of fasting and stimulated insulin and C-peptide concentrations in the diabetics indicated either increased insulin disappearance rates or decreased C-peptide clearance rates. Faber et al. (33) have previously reported normal C-peptide clearance rates in insulin-dependent diabetics, so that increased insulin disappearance may be more iikely. This agrees with an earlier, preliminary report from our laboratory (34), but has not been a universal finding (35-40). More detailed studies of insulin and C-peptide kinetics in these diabetics are needed before firm conclusions can be drawn regarding possible abnormalities of insulin or C-peptide catabolic rates.

Our rejection of the view that marked hyperglycemia in subjects with NIDDM is a result merely of decreased insulin action is based upon our inability to document a significant negative correlation between insulin-stimulated glucose disposal rates and degree of fasting hyperglycemia. DeFronzo and associates (41), using a "low-dose" insulin infusion, reported a weak $(r=-0.30,0.05<P<0.1)$ correlation between FPG and glucose metabolic clearance rate in 27 lean Caucasian subjects with NIDDM. We also analyzed the data of Kolterman et al. (6) including only results from subjects with NIDDM. Their data show a significant relationship $(r=-0.48, P<0.02)$ between insulin action and fasting serum glucose concentration at maximally stimulating insulin concentrations. Overall, however, the implication of the three studies appear similar. We found that none of the variance in FPG of diabetics was attributable to differences in insulin-stimulated glucose disposal rates, whereas DeFronzo et al. (41) and Kolterman et al. (6) found that differences in insulin action could account for 9 and $23 \%$ of the variance in their studies. It appears that decreases in insulin-stimulated glucose disposal can explain only a small part of the variation in fasting hyperglycemia in noninsulin-dependent diabetic subjects.

In conclusion, moderately increased fasting glycemia in some nondiabetics and in mildly hyperglycemic noninsulindependent diabetics appeared to be primarily a result of decreased insulin action. Marked hyperglycemia in the diabetics occurred as a result of both decreased insulin action and decreased peripheral insulin concentrations. We hypothesize that the major results of these changes in insulin action and secretion are increased FFA concentrations, increased fat oxidation, and increased flux of gluconeogenic substrates to the liver, leading to increased EGPR and progressive hyperglycemia.

\section{Acknowledgments}

We thank Ms. Robinson and the nursing staff of the Phoenix Clinical Research Section for nursing support; Verna Kuwanhoyioma for secretarial help; Thomas Anderson, John Brown, Karen Stone, Inge Harper, Annette Kennedy, Vicki Mongillo, Vera Rodriguez, and Pamela Thuillez for technical assistance. Most of all, we thank the Indian volunteers.

\section{References}

1. Reaven, G. M. 1980. Insulin-independent diabetes mellitus: metabolic characteristics. Metab. Clin. Exp. 29:445-454.

2. Reaven, G. M. 1983. Insulin resistance in noninsulin-dependent diabetes mellitus. Does it exist and can it be measured? Am. J. Med. 74:3-17.

3. Reaven, G. M., W. S. Sageman, and R. S. Swenson. 1977. Development of insulin resistance in normal dogs following alloxaninduced insulin deficiency. Diabetologia. 13:459-462.

4. Kobayashi, M., and J. M. Olefsky. 1979. Effects of streptozotocininduced diabetics on insulin binding, glucose transport, and intracellular glucose metabolism in isolated rat adipocytes. Diabetes. 28:87-95.

5. Karnielli, E., P. J. Hissin, I. A. Simpson, L. B. Salans, and S. W. Cushman. 1981. A possible mechanism of insulin resistance in the rat adipose cell in streptozotocin-induced diabetes mellitus. Depletion of intracellular glucose transport systems. J. Clin. Invest. 68:811-814.

6. Kolterman, O. G., R. S. Gray, J. Griffin, P. Burstein, J. Insel, J. A. Scarlett, and J. M. Olefsky. 1981. Receptor and post-receptor defects contribute to the insulin resistance in non-insulin dependent diabetes mellitus. J. Clin. Invest. 68:957-969.

7. Reaven, G. M., and R. Miller. 1968. Study of the relationship between glucose and insulin response to an oral glucose load in man. Diabetes. 17:560-569.

8. Reaven, G. M., R. Bernstein, B. Davis, and J. M. Olefsky. 1976. Non-ketotic diabetes mellitus: insulin deficiency or insulin resistance? Am. J. Med. 60:80-88.

9. Savage, P. J., S. E. Dippe, P. H. Bennett, P. Gorden, J. Roth, N. Rushforth, and M. Miller. 1974. Hyperinsulinemia and hypoinsulinemia. Insulin responses to oral carbohydrate over a wide spectrum of glucose tolerance. Diabetes. 24:362-368.

10. Liu, G., A. Coulston, Y.-D. I. Chen, and G. M. Reaven. 1983. Does day-long absolute hypoinsulinemia characterize the patient with non-insulin-dependent diabetes mellitus? Metab. Clin. Exp. 32:754756.

11. DeFronzo, R. A., and E. Ferrannini. 1982. The pathogenesis of non-insulin-dependent diabetes. An update. Medicine. 61:125-140. 
12. Goldman, R. F., and E. R. Buskirk. 1961. A method for underwater weighing and the determination of body density. In Techniques for Measuring Body Composition. J. Brozek, and A. Herschel, editors. National Academy of Sciences, New York. 78-89.

13. National Diabetes Data Group. 1979. Classification and diagnosis of diabetes mellitus and other categories of glucose intolerance. Diabetes. 28:1039-1057.

14. Lusk, G. 1924. Animal calorimetry. Analysis of oxidation of mixtures of carbohydrate and fat. J. Biol. Chem. 59:41-42.

15. Steele, R. 1959. Influences of glucose loading and of injected insulin on hepatic glucose output. Ann. NY Acad. Sci. 82:420-430.

16. Herbert, V., K. Lau, C. W. Gotlieb, and S. J. Bleicher. 1965. Coated charcoal immunoassay of insulin. J. Clin. Endocrinol. Metab. 25:1375-1384.

17. Yalow, R. S., and S. A. Berson. 1960. Immuoassay of endogenous plasma insulin in man. J. Clin. Invest. 39:1157-1167.

18. Hedin, L. G. 1975. Radioimmunological determination of human C-peptide in serum. Diabetologia. 11:541-48.

19. Frank, B. H., J. M. Pettee, R. E. Zimmerman, and P. J. Burek. 1981. The production of human proinsulin and its transformation to human insulin and C-peptide. In Peptides: Synthesis-Structure Function. E. H. Rich, and E. Gross, editors. Pierce Chemical Co., Rockford, IL. 729-738.

20. Frank, B. H., M. J. Beckage, and K. A. Wiley, 1983. Highperformance liquid chromatographic preparation of single-site carrierfree pancreatic polypeptide hormone radiotracers. J. Chromatogr. 266:239-248.

21. Best, J. D., R. G. Judzewitsch, M. A., Pfeifer, J. C. Beard, J. B. Halter, and D. Porte, Jr. 1982. The effect of chronic sulfonylurea therapy on hepatic glucose production in non-insulin dependent diabetes. Diabetes. 31:333-338.

22. Howard, B. V., P. J. Savage, M. Nagulesparan, L. J. Bennion, R. H. Unger, and P. H. Bennett. 1979. Evidence for marked sensitivity to the antilipolytic action of insulin in obese maturity-onset diabetics. Metab. Clin. Exp. 28:744-749.

23. Bogardus, C., S. Lillioja, K. Stone, and D. Mott. 1984. Correlation of muscle glycogen synthase activity and in vivo insulin action in man. J. Clin. Invest. 73:1185-1190.

24. Lillioja, S., C. Bogardus, and D. Mott. 1984. The glucose-fatty acid cycle determines glucose oxidation but not total insulin-mediated glucose disposal in man. Clin. Res. 32(2):401A.

25. Randle, P. J., P. B. Garland, C. N. Hales, and E. A. Newsholme. 1963. The glucose fatty-acid cycle: its role in insulin sensitivity and the metabolic disturbances of diabetes mellitus. Lancet. I:785-789.

26. Ward, W. K., J. B. Halter, J. C. Beard, and D. Porte Jr. 1984. Adaptation of $\mathbf{B}$ and $A$ cell function during prolonged glucose infusion in human subjects. Am. J. Physiol. 246(Endocrinol. Metab. 9):E405E411.

27. Aronoff, S. L., P. H. Bennett, P. Gorden, N. Rushforth, and
M. Miller. 1977. Unexplained hyperinsulinemia in normal and prediabetic Pima Indians compared with normal Caucasians. Diabetes. 26:827-840.

28. Ruderman, N. B., C. J. Toeus, and E. Shafrir. 1969. Role of free fatty acids in glucose homeostasis. Arch. Intern. Med. 123:299313.

29. Blumenthal, S. A. 1983. Stimulation of gluconeogenesis by palmitic acid in rat hepatocytes: evidence that this effect can be dissociated from provision of reducing equivalents. Metab. Clin. Exp. 32:971-976.

30. Ferrannini, E., E. J. Barrett, S. Beuilacqua, and R. A. DeFronzo. 1983. Effect of fatty acids on glucose production and utilization in man. J. Clin. Invest. 72:1737-1747.

31. Felig, P., J. Wahren, and R. Hendler. 1978. Influence of maturity-onset diabetes on splanchnic glucose tolerance after oral glucose ingestion. Diabetes. 27:121-126.

32. Hagenfeldt, L. 1979. Metabolism of free fatty acids and ketone bodies during exercise in normal and diabetic man. Diabetes. 28:(Suppl. 1):66-70.

33. Faber, O. K., C. Hagen, C. Binder, J. Makussen, V. K. Naithani, P. M. Blix, H. Kuzuya, D. L. Horowitz, A. H. Rubenstein, and N. Rossing. 1978. Kinetics of human connecting peptide in normal and diabetics subjects. J. Clin. Invest. 62:197-203.

34. Vasquez, B., G. M. Reaven, and W. J. Andrews. 1983. Elevated in vivo insulin clearance in noninsulin dependent diabetes. Clin. Res. 31(1):61 A.

35. Orskov, H., and N. J. Christensen. 1969. Plasma disappearance rate of injected human insulin in juvenile diabetic, maturity-onset diabetic and nondiabetic subjects. Diabetes. 18:653-659.

36. Frost, D. P., M. C. Srivastava, R. H. Jones, J. D. N. Nabarro, and P. H. Sonkson. 1973. The kinetics of insulin metabolism in diabetes mellitus. Postgrad. Med. J. 49:949-954.

37. Palumbo, P. J., W. F. Taylor, G. D. Molnar, and W. N. Tauxe. 1972. Disappearance of bovine insulin from plasma in diabetic and normal subjects. Metab. Clin. Exp. 21:787-798.

38. Navalesi, R., A. Pilo, and E. Ferrannini. 1978. Kinetic analysis of plasma insulin disappearance in nonketotic diabetic patients and in normal subjects. A tracer study with ${ }^{125} \mathrm{I}$-insulin. J. Clin. Invest. 61:197-208.

39. McGuire, E. A., J. D. Tobin, M. Berman, and R. Andres. 1979. Kinetics of native insulin in diabetic, obese and aged men. Diabetes. 28:110-120.

40. Stimmler, L. 1976. Disappearance of immunoreactive insulin in normal and adult-onset diabetic patients. Diabetes. 16:652-655.

41. DeFronzo, R. A., D. Simonson, and E. Ferrannini. 1982. Hepatic and peripheral insulin persistance: a common feature of type 2 (non-insulin-dependent) and type I (insulin-dependent) diabetes mellitus. Diabetologia. 23:313-319. 